\section{Research Square}

Preprints are preliminary reports that have not undergone peer review.

They should not be considered conclusive, used to inform clinical practice, or referenced by the media as validated information.

\title{
Life satisfaction, worthwhileness of life and leisure activities among older people: assessing the mediating effect of self-reported health limitations
}

\author{
K.E. Hancock ( $\nabla$ k.hancock@lboro.ac.uk) \\ School of Sport, Exercise and Health Sciences, Loughborough University https://orcid.org/0000-0002-8453-2623 \\ L.B. Sherar \\ National Centre for Sport and Exercise Medicine, Loughborough University https://orcid.org/0000-0002-9942-5433 \\ P. Downward \\ School of Sport, Exercise and Health Sciences https://orcid.org/0000-0002-6374-4176
}

\section{Research Article}

Keywords: Subjective wellbeing, Leisure activities, Health limitations, Mediation analysis, Older people

Posted Date: April 13th, 2021

DOI: https://doi.org/10.21203/rs.3.rs-405611/v1

License: @) (i) This work is licensed under a Creative Commons Attribution 4.0 International License. Read Full License 


\section{Abstract}

What makes life worthwhile is an under-researched dimension of subjective wellbeing (SWB) but important for older people. Leisure participation is positively related to SWB, but SWB reduces with poor health, and health deteriorates with age. Drawing on pooled cross-sectional Taking Part Surveydata on almost 7,000 English adults aged 50+ from 2016/17-2018/19, we investigated relationships between different leisure activities and life satisfaction and worthwhileness. The analyses further explored the mediating effects of limiting long-standing illness and/or disability.

Before accounting for health limitations, participating in exercise-related physical activity (i.e., sport and exercise) and a greater number of different leisure activities were positively associated with both SWB dimensions. Passive mental activities (e.g., TV-watching) were negatively associated with SWB. Other physical activities (i.e., activities of daily living, e.g., gardening, active travel); social activities; cultural activities (e.g., visiting museums, cinemas) and hobbies (e.g., handicrafts, music-making) were associated with worthwhileness. Using Structural Equation Modelling we showed the mediating effect of health limitations varied with SWB dimension and different leisure activities. Positive associations between social and culture/hobby activities and SWB were not mediated by poor health; neither was the negative association between passive mental activities and SWB. The positive association between exercise-related physical activity and SWB was mediated by health limitations more than other physical activities. Overall, poor health mediated the association between worthwhileness and leisure activities less than life satisfaction. Promoting a range of activities contributing to feelings of worthwhileness may provide a route to enhanced wellbeing, despite declining health among older people.

\section{Declarations}

Funding - No funding was received for conducting this study.

Conflicts of interest - The authors have no relevant financial or non-financial interests to disclose.

Availability of data and material - Taking Part Survey data was obtained from the UK Data Service.

DOls: 2016/2017 - Year 12 survey - http://doi.org/10.5255/UKDA-SN-8378-2

2017/2018 - Year 13 survey - http://doi.org/10.5255/UKDA-SN-8442-1

2018/2019 - Year 14 survey - http://doi.org/10.5255/UKDA-SN-8631-1

Code availability - Stata code written to manipulate and analyse the data is available from the corresponding author on request.

Authors' contributions - All authors contributed to the study conception and design. Material preparation, data extraction and analysis were performed by Karen Hancock. The first draft of the manuscript was written by Karen Hancock and all authors commented on previous versions of the manuscript. All authors read and approved the final manuscript.

Ethics approval - Not applicable. The ethical clearance process at Loughborough University was followed, which indicated that that there are no ethical requirements needing scrutiny for the publicly available secondary data used in this research.

Consent to participate - Not applicable.

Consent for publication - Not applicable. 
Finding meaning and purpose in life can become more challenging as people age. Time spent on career and family shrinks, physical strength and capabilities diminish, and social connections reduce (Mckenna et al., 2007). A strong sense of meaning and purpose in life has been associated with living longer, less disability (Ong \& Patterson, 2016), better health-related quality of life (Steptoe \& Fancourt, 2019), and other markers of successful ageing (Pinquart, 2002; Urtamo et al., 2019). Feeling that life is worthwhile and meaningful is a component of subjective wellbeing and one of the two evaluative dimensions of national wellbeing monitored by the UK's Office for National Statistics since 2011 (Office for National Statistics, 2013). The other evaluative dimension is life satisfaction (Office for National Statistics, 2018). Empirical research has focused primarily on the correlates and determinants of life satisfaction and an evaluative measure of happiness (Clark, 2018), much less so on the correlates and determinants of worthwhileness (Crespo \& Mesurado, 2015; Dolan \& Kudrna, 2016; What Works Centre for Wellbeing, 2021). Feelings about worthwhileness of life correspond broadly to the Aristotelean notion of "eudaimonia" or flourishing, i.e., living a life that has meaning and purpose that satisfies deeper psychological needs (Joshanloo, 2016; Ryff, 2017). Understanding the determinants of feelings of worthwhileness among older people alongside those that influence life satisfaction would - to the extent they differ from the determinants of life satisfaction - provide another route to improving older people's wellbeing and possibly health (Ong \& Patterson, 2016; Steptoe \& Fancourt, 2019).

Feeling that life is worthwhile is concerned with the things you do in life (Office for National Statistics, 2018). An individual has more agency over leisure activities compared with activities undertaken in other contexts, i.e., work, business, family obligations, and necessary activities of daily living like eating, sleeping and washing (Stebbins, 2005). Arguably choice of leisure activities can help people achieve a balance between pleasure and purpose in life (Dolan, 2014). There is now much research demonstrating that participation in different kinds of leisure activities brings a range of physical and mental health benefits for older people (see references in Fancourt et al., (2021), supporting the activity theory of ageing (Havighurst, 1961). However, it is important to recognise that health limitations and SWB are closely linked to age (Steptoe et al., 2015), and that individual responses to both ageing and health limitations vary (Ryff, 2017). Selection, optimisation, and compensation theory links choice of activities, age and successful ageing (Baltes \& Carstensen, 2003; Freund \& Baltes, 1998). The theory sees successful ageing as a lifelong process of maximising gains and minimising losses through actively employing selection, optimisation, and compensation strategies. Selection involves revising goals to reflect strengths and intact abilities (e.g., replacing employment with volunteering or substituting cycling for running as a sport); optimisation means acquiring goal-relevant means to maximise gains (e.g., joining volunteer or cycling organisations to enhance networks); compensation refers to processes that minimise losses (e.g., using spectacles to read). Thus, individuals who are ageing successfully are likely to choose different leisure activities and/or engage with them in different ways as an adaptive response to ageing. Understanding what leisure activities older people choose to help them feel that life is worthwhile despite health limitations can help inform services and programmes to promote successful ageing.

\section{Leisure Activities And Subjective Wellbeing Among Older People}

A number of studies have found positive associations between the frequency and diversity of engagement in leisure activity in general and various measures of subjective wellbeing among older and/or retired people, as identified in the systematic review and meta-analysis of Kuykendall et al., (2015). The same review also found experimental evidence that interventions to enhance leisure satisfaction (wellbeing derived specifically from leisure activities) increased subjective wellbeing in elderly and disabled people, and meta-analytic support for a path model in which measures of leisure satisfaction mediated the relationship between leisure engagement and subjective wellbeing. However, although this review used health as a confounding variable to explain variation in subjective wellbeing measures and discussed possible spill-over effects between health and leisure satisfaction, the study did not explicitly model any links between leisure participation, health and subjective wellbeing. Some studies which do explicitly model such a link have found frequency of participation in leisure activities acts as a mediator between physical health and wellbeing in older people (Chang et al., 2014; Ihle et al., 2017; Paggi et al., 2016).

It is well established that physical activity is positively related to various measures of wellbeing in older people (Bae et al., 2017; Dolan et al., 2014; Fortier \& Morgan, 2021; Rasciute \& Downward, 2010; Zhang \& Chen, 2019). Participation in social activities has also consistently been shown to be positively related to older people's life satisfaction (Adams et al., 2011; Lam \& Garcia, 2019; Michèle et al., 2019; Ryu \& Heo, 2018) and psychological wellbeing (Sharifian \& Grühn, 2019), which aligns with evidence that good social relationships in old age are better for health (Musich et al., 2018; Tkatch et al., 2017), and that leisure activities can help mediate the association between social relationships and health (Chang et al., 2014). Other leisure activity types that have been shown to be positively related to SWB in older adults include volunteering (Ryu \& Heo, 2018); and participating in community groups (Michèle et al., 2019) such as arts, education or music groups and church or religious groups (Fancourt \& Steptoe, 2018a). One challenge with drawing general conclusions from this literature is the lack of standardisation in the definitions and scope of different leisure activities (Adams et al., 2011). Adams' (2011) critical review noted that most studies of the relationships between social and leisure activities and wellbeing in older people reported on two or three broad leisure activity domains, i.e., informal/formal/solitary, or productive/leisure. 
Some general conclusions can be drawn from the aforementioned. First, the frequency and diversity of leisure engagement is associated with greater life satisfaction in older people, supporting activity theory, and leisure engagement reduces with physical limitations that increase with age. Second, leisure engagement may mediate the relationship between physical limitations and life satisfaction. There is most evidence for positive associations between physical and social activities and life satisfaction and some support for positive effects of cultural activities and hobbies (Brown et al., 2015), but these are rarely studied. Having good social relationships is also important for health, and leisure activities can also mediate this effect. Finally, there are a number of different mediation models proposed and investigated: leisure satisfaction mediates the link between leisure engagement and wellbeing; leisure participation mediates the link between physical activity and wellbeing; and leisure participation mediates the link between social relationships and health. Although there is some suggestion in these studies that there may be a link between reduced leisure engagement and age, the idea from selection, optimisation and compensation theory that older people might choose leisure activities to maintain their feelings of wellbeing in the face of health limitations that increase with age has not been investigated to our knowledge.

The empirical literature investigating the factors linked to eudaimonic wellbeing, flourishing or feeling that life is worthwhile is much smaller than that relating to life satisfaction (What Works Centre for Wellbeing, 2021). For older people, the number of leisure activities engaged in was associated with a measure of flourishing in a small Croatian study (Kaliterna Lipovčan, L., Brkljačić, T., Prizmić Larsen, Z., Brajša-Žganec, A., \& Franc, 2018). In terms of specific activities, there is evidence from Korean adults of all ages that volunteering enhances eudaimonic and social well-being (but not hedonic well-being) (Son \& Wilson, 2012). At least two studies link participation in learning and measures of eudaimonic wellbeing among older people (Jenkins \& Mostafa, 2015; Narushima et al., 2013). The most comprehensive study of factors associated with feelings of worthwhileness among older people used longitudinal data on English over 50 s to estimate regression models of worthwhileness (Steptoe \& Fancourt, 2019). Although not specifically focusing on leisure activities, they found higher worthwhileness was associated both crosssectionally and longitudinally with stronger personal relationships, wider social engagement (e.g., volunteering), greater income and wealth, better self-rated physical and mental health, better objective health indicators, better health behaviours, more time spent in social activities, working or volunteering and walking/exercising and less time spent alone or watching television. The finding that worthwhileness levels predicted a wide range of outcomes independent of baseline levels in the longitudinal analysis suggests that having higher worthwhileness may contribute to better health and more successful ageing. These results were strengthened in a follow-up study which found evidence for bi-directional relationships between health, activities, health behaviours and feelings of worthwhileness (Steptoe \& Fancourt, 2020). The study is one of a few that links a eudaimonic measure of wellbeing to health outcomes (see also Musich et al., (2018)). None of these studies however sheds light on how health factors may be related to the choice of activities or use of leisure time, and thus to feelings of worthwhileness of life.

\section{The Influence Of Health Limitations On Leisure Participation And Wellbeing}

About 40 per cent of people in the UK over the age of 65 have a limiting long-term health condition, such as diabetes, heart disease, respiratory disease, cancer, arthritis or dementia (Alessi \& Rashbrook, 2016). Many also suffer from musculo-skeletal problems and/or chronic pain that limits their activities. The probability of having a musculoskeletal condition increases monotonically with age such that more than half of those 65 and over are affected (Versus Arthritis, 2019). Health and physical limitations are often mentioned as an important barrier to physical activity and exercise among older people (Bethancourt et al., 2014; Biedenweg et al., 2014; Cox et al., 2006; Justine et al., 2013; Library Research Service, 2010; Moschny et al., 2011). Thus, despite the many beneficial effects for older people's health and wellbeing from leisure activities, particularly physical and social activities (see review in Fancourt et al., (2021)), health limitations are likely to affect the choice of, and manner of engagement with activities according to selection, compensation and optimisation theory. Several cross-sectional studies have shown that leisure engagement and participation is lower in people with poorer health, who are also usually older people (Galenkamp et al., 2016; Nilsson et al., 2017). However, there appear to be no studies that explore the mediating effects of health limitations on feelings of both life satisfaction and worthwhileness associated with participation in different leisure activities.

\section{Research Questions}

In summary, we argue it would be useful to understand which leisure activities are associated with feelings of life satisfaction and worthwhileness for older people and how those feelings are mediated by health limitations as these are research gaps identified in our survey of the literature, which, if filled, could help improve the effectiveness of policy and practice to improve the SWB of older people. The main research question addressed by this study is: how are different types of leisure activity associated with life satisfaction and worthwhileness? A second research question is does having health limitations mediate these relationships? Finally, following from this, the study addresses the question of whether any mediating effect of health limitations affects relationships between leisure activity participation and life satisfaction differently from relationships between leisure activity participation and feelings of worthwhileness. Figure 1 sets out the hypothesised links. It is expected that participation in most leisure activities is positively associated with each dimension of subjective wellbeing directly. However, health limitations seem likely to have a negative relationship with participation in at least some leisure activities, and also to have a negative relationship with 
subjective wellbeing. These two negative links comprise the indirect or mediating effect of health limitations. They dampen the total effect of leisure participation on subjective wellbeing.

[ Insert Fig 1 here]

\section{Methods And Data}

We used data from the Department for Digital, Culture, Media and Sport's Taking Part Survey (TPS), which commenced in 2005 and collects information on participation in a wide range of leisure activities in England to investigate these issues (Department for Digital Culture Media and Sport, 2020). The TPS includes a large sample of adults, with information on both life satisfaction and worthwhileness of life, personal characteristics, and participation in a wide range of activities. Whilst a longitudinal sub-sample of the data is available, it suffers from high attrition rates. Therefore, in common with some other published studies

(Downward et al., 2018; Rasciute \& Downward, 2010), data from several years were pooled for this study. Waves 12 -14 (2016-2017 to 2018-2019) were selected as they include both life satisfaction and worthwhileness measures of SWB and data on household income, which has been found to be an important correlate of life satisfaction in previous studies (Dolan et al., 2008). The data were downloaded from the UK Data Service (Department for Culture Media and Sport, 2018, 2019, 2020). The total sample included 21,269 adults. Of these, 11,458 were aged 50+. Selecting out cases with missing values for any of the variables used in the analyses left a usable analytical sample of 6,839 . Table 1 shows the distributions of the demographic and survey control variables used in the analyses for the original and analytical datasets for adults aged $50+$.

The presence of a limiting long-standing illness or disability was used as a measure of health limitations, as this has been found to be a statistically significant measure of health relating to participation in leisure activities (Paggi et al., 2016). The question asked to elicit the presence of limiting longstanding illness uses the ONS harmonised wording (Nixon, 2020). Almost half the sample (45.1\%) had a limiting long-standing illness or disability. The proportion increased monotonically with age-band from 31.4\% among 50-54s to 63.2\% among those aged 80+. Twelve demographic variables including ageband, gender, relationship status etc, were used to control for factors found to be related to the evaluative dimensions of SWB in previous studies (Dolan et al., 2008). Household income was equivalised to take account of differences in household size and composition which affect the standard of living that can be afforded from a given income (see note a to Table 1). Finally, TPS-specific controls for year of survey and whether the fieldwork was carried out in winter (January-March) were included.

Table 1 Distributions of key variables from original dataset aged 50+ and analytical dataset 


\begin{tabular}{|c|c|c|}
\hline Variable & $\begin{array}{l}\text { Original dataset } \\
(\mathrm{n}=11,458)\end{array}$ & $\begin{array}{l}\text { Analytical dataset } \\
\qquad(\mathrm{n}=6,839)\end{array}$ \\
\hline \multicolumn{3}{|l|}{ Gender } \\
\hline No. (\%) missing values & $0 \quad(0.0 \%)$ & \\
\hline $1=$ 'Male' & $5,213(45.5 \%)$ & $3,309(48.4 \%)$ \\
\hline $2={ }^{\prime}$ Female' & $6,242(54.5 \%)$ & $3,529(51.6 \%)$ \\
\hline $3=$ 'Other' & $3(0.03 \%)$ & $1(0.01 \%)$ \\
\hline \multicolumn{3}{|l|}{ Age band } \\
\hline No. (\%) missing values & $70 \quad(0.6 \%)$ & \\
\hline $8={ }^{\prime} 50-54 '$ & $1,703(14.9 \%)$ & $1,103(16.1 \%)$ \\
\hline $9=` 55-59 ’$ & $1,715(15.0 \%)$ & $1.085(15.9 \%)$ \\
\hline $10=' 60-64 '$ & $1,704(14.9 \%)$ & $1,056(15.4 \%)$ \\
\hline $11={ }^{\prime} 65-69^{\prime}$ & $1,792(15.6 \%)$ & $1,132(16.6 \%)$ \\
\hline $12=' 70-74 ’$ & $1,716(15.0 \%)$ & $1,019(14.9 \%)$ \\
\hline $13=` 75-79^{\prime}$ & $1.118(10.4 \%)$ & $665 \quad(9.7 \%)$ \\
\hline $14=^{\prime} 80+^{\prime}$ & $1,640(14.3 \%)$ & $779(11.4 \%)$ \\
\hline \multicolumn{3}{|l|}{ Equivalent annual income per head $(£ 000)^{\mathrm{a}}$} \\
\hline \multicolumn{3}{|l|}{ No. (\%) missing values } \\
\hline Mean (s.d.) & 3,309 (28.9\%) & \\
\hline Has limiting long-standing illness/disability & $£ 27.2(£ 18.1)$ & $£ 27.1(£ 17.8)$ \\
\hline \multicolumn{3}{|l|}{ No. (\%) of missing values } \\
\hline \multirow{3}{*}{$\begin{array}{l}\text { Relationship status } \\
\qquad \begin{array}{l}\text { No. (\%) missing values } \\
1=\text { 'Living in a couple' }\end{array}\end{array}$} & $95(0.8 \%)$ & \\
\hline & $5,231(45.7 \%)$ & $3.086(45.1 \%)$ \\
\hline & $101(0.9 \%)$ & \\
\hline \multirow{2}{*}{\multicolumn{3}{|c|}{$\begin{array}{l}\text { Currently practising a religion } \\
\text { No. (\%) missing values } \\
1=\text { "Yes' }\end{array}$}} \\
\hline & & \\
\hline Non-white ethnicity & $2,972(25.9 \%)$ & \\
\hline $\begin{array}{r}\text { No. (\%) missing values } \\
1=\text { 'Yes' }\end{array}$ & $3,457(40.8 \%)$ & $1,971(28.8 \%)$ \\
\hline Has some housing equity & $38(0.3 \%)$ & \\
\hline \multirow{2}{*}{\multicolumn{3}{|c|}{$\begin{array}{l}\text { No. (\%) missing values } \\
1=\text { 'Yes' }\end{array}$}} \\
\hline & & \\
\hline Has a degree or equivalent & $2(0.0 \%)$ & \\
\hline $\begin{array}{r}\text { No. (\%) missing values } \\
1=\text { 'Yes' }\end{array}$ & $8,735(76.2 \%)$ & $5,220(76.3 \%)$ \\
\hline \multicolumn{3}{|l|}{$\begin{array}{ll} & 1=\text { 'Yes' } \\
\text { Area type } & \end{array}$} \\
\hline $\begin{array}{r}\text { No. (\%) missing values } \\
1=\text { 'Urban' }\end{array}$ & $2,767(36.2 \%)$ & $1,788(26.1 \%)$ \\
\hline English not first language & $1(0.0 \%)$ & \\
\hline $\begin{array}{r}\text { No. (\%) missing values } \\
1=\text { 'Yes' }\end{array}$ & $9,045(79.0 \%)$ & $5,363(78.3 \%)$ \\
\hline Socio-economic status & $4(0.0 \%)$ & \\
\hline No. (\%) missing values & $489(4.3 \%)$ & $233(3.1 \%)$ \\
\hline $1=$ 'higher managerial' & & \\
\hline $2=$ 'intermediate' & $572(5.3 \%)$ & \\
\hline $3=$ 'routine/manual' & $3,964(36.4 \%)$ & $2,672(39.1 \%)$ \\
\hline $4=$ 'never worked/unemployed/not classified' & $2,271(20.9 \%)$ & $1,379(20.2 \%)$ \\
\hline Has $1+$ children at home & $4,127(37.9 \%)$ & $2,576(37.7 \%)$ \\
\hline $\begin{array}{l}\text { No. (\%) missing values } \\
1 \text { = 'Yes' }\end{array}$ & $524(4.8 \%)$ & $212(3.1 \%)$ \\
\hline \multicolumn{3}{|l|}{ Employment status } \\
\hline No. (\%) missing values & $27(0.2 \%)$ & \\
\hline $1=$ 'In employment, education or training' & $577(5.0 \%)$ & $362(5.3 \%)$ \\
\hline $2={ }^{\prime}$ Unemployed/long-term sick’ & & \\
\hline $3=$ 'Wholly retired' & $1,309(11.4 \%)$ & \\
\hline 4 = 'Home carer' & & \\
\hline Year of survey & & \\
\hline & $3,506(30.6 \%)$ & $2,533(37.0 \%)$ \\
\hline & $615(5.4 \%)$ & $394(5.8 \%)$ \\
\hline & $5,821(50.8 \%)$ & $3,737(54.6 \%)$ \\
\hline & 207 (1.8\%) & $175(2.6 \%)$ \\
\hline No. (\%) missing values & $0(0.0 \%)$ & \\
\hline $12=' 2016-17 ’$ & $2,863(25.0 \%)$ & $1,500(21.9 \%)$ \\
\hline $13=' 2017-18 ’$ & $4,152(36.2 \%)$ & $2,465(36.0 \%)$ \\
\hline $14=' 2018-19 '$ & $4.443(38.8 \%)$ & $2,874(42.2 \%)$ \\
\hline Winter (surveyed Jan-Mar) & & \\
\hline No. (\%) of missing values & $0(0.0 \%)$ & \\
\hline & $2,947(25.7 \%)$ & $1,908(28.1 \%)$ \\
\hline
\end{tabular}

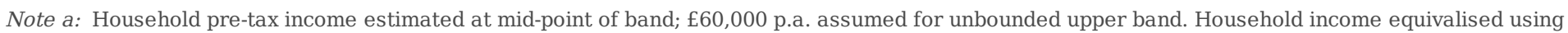

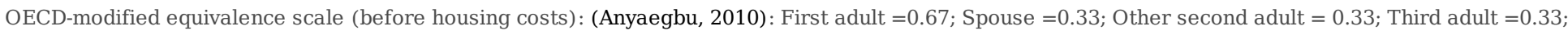
Subsequent adults $=0.33$; Each dependent aged: 0 to $13=0.20 ; 14+=0.33$; 16 or over $=0.33$. 


\section{Variables}

Table 2 shows definitions and descriptive statistics for the SWB variables and leisure activity participation measures used in the analysis. The life satisfaction and worthwhileness of life dimensions of SWB are measured using the same question wording as the comparable ONS measures of personal wellbeing (Office for National Statistics, 2018). Both are measured on a 0-10 scale, where 0 means "not at all satisfied" or "not at all worthwhile" and 10 is "completely satisfied" or "completely worthwhile". The TPS measures engagement in a wide range of leisure activities across six sectors of policy interest to the Department of Culture, Media and Sport. The sectors comprise the arts; museums and galleries; archives; libraries; heritage and sport. The sport category includes all recognised sports, all types of dance, walking or cycling for sport or leisure, and any fitness activity, whether performed alone or in a class. Frequency of walking and cycling for purposes of travel (i.e., active travel) is measured separately. The survey also asks about participation in a range of free-time activities (e.g., eating out, giving to charity, watching TV etc). Some grouping of the many heterogeneous activities available in the TPS into 'domains' (Adams et al., 2011) was undertaken, as the expectation is that health limitations would pose more barriers to participating in some types of activities than others. Using prior assumptions about the nature of different activities, we grouped activities into physical; mental; social; and culture/hobbies. Physical activities were sub-divided into "exercise-related physical activity" (all active sports, including dance and fitness activities, plus recreational cycling and walking) for which the primary purpose is the activity itself, and "other physical activities" (gardening, DIY, shopping and active travel) where the physical effort is not the primary purpose of the activity (Caspersen et al., 1985). Mental activities were sub-divided into cognitively active (reading, writing, listening to music, playing computer games) and cognitively passive mental activities (watching TV and internet surfing) as previous research suggests more cognitively active mental activities are associated with higher SWB and healthier ageing than cognitively passive mental activities (Iizuka et al., 2019; Stenner \& Mcfarquhar, 2011; Verghese et al., 2003). Social activities were subdivided into personal social (friends and family time, eating out and visiting pubs and clubs) and prosocial activities (volunteering and giving to charity). The culture/hobbies domain includes days out to places of interest, heritage sites, museums, archives or galleries; participating in or attending live arts or sporting events; and taking part in creative hobbies such as making music, art, photography, cookery, woodwork, or crafts for example. These seven sub-domains are similar to broad categories used in several previous studies on leisure participation and wellbeing in older people, e.g., (Brajša-Žganec et al., 2011; Hallmann et al., 2017; Lee et al., 2018; Ryu \& Heo, 2018). By further disaggregation of the culture/hobbies and social domains, we also constructed a variable that is a count of the number of different types of leisure activity the participant engages in, up to a maximum of 11 . This variable is intended to capture the central idea of activity theory (Havighurst, 1961) and more modern theories of successful ageing (Bowling \& Dieppe, 2005) that participation in a greater number of different types of activity is a sign of a highly engaged and optimistic older person who is more likely to have higher SWB than one whose range of leisure activities is narrower. Activity participation frequency is measured in a variety of ways in the TPS. Questions relating to sport and active travel ask about frequency over the last 28 days. Questions relating to participation in arts and cultural activities, volunteering and giving to charity ask about frequency in the last 12 months. And questions about participation in non-DCMS target activities ask a binary question about whether the respondent participates in this activity (e.g., eating out, reading, DIY, gardening etc.) in their free time. In all cases, these frequencies were recoded into 0,1 dummy variables where 1 represents a frequency specific to the leisure activity type as shown in Table 2 .

Table 2 Descriptive statistics for SWB and activities variables 


\begin{tabular}{|c|c|c|c|c|c|c|}
\hline Variable label & $\begin{array}{l}\text { Variable } \\
\text { name }\end{array}$ & Definition & Variable & $\begin{array}{c}\text { Value } \\
\text { labels (if } \\
\text { categorical) }\end{array}$ & $\begin{array}{l}\text { Mean* } \\
\text { Frequency }\end{array}$ & $\begin{array}{c}(\text { s.d.*) } \\
(\%)\end{array}$ \\
\hline Life satisfaction & SATIS & $\begin{array}{l}\text { How satisfied are you with life nowadays? ( } 0-10 \text { scale), } 0 \\
=\text { "not at all satisfied"; } 10=\text { "completely satisfied". }\end{array}$ & & & $7.83 *$ & $(1.88)^{*}$ \\
\hline
\end{tabular}

Continuous

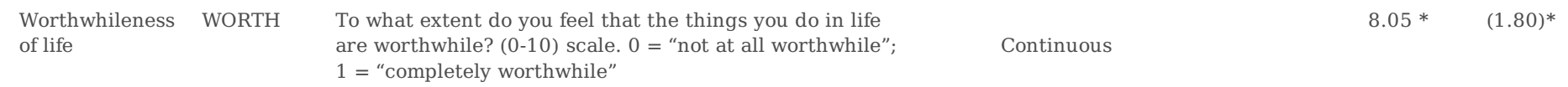

\begin{tabular}{|c|c|c|c|c|c|c|}
\hline No. activities & nacts & No. of different types of leisure activity (0-11) & Continuous & & $8.56^{*}$ & $(2.1)^{*}$ \\
\hline $\begin{array}{l}\text { Exercise- } \\
\text { related physical } \\
\text { activity }\end{array}$ & ExPA & $\begin{array}{l}\text { Structured PA for sport, fitness or leisure at least } 3 \text { times } \\
\text { in last } 28 \text { days }\end{array}$ & Binary & $\begin{array}{c}1 \text { = 'yes' } \\
0=\text { 'no' }\end{array}$ & 5,431 & $(79.4)$ \\
\hline $\begin{array}{l}\text { Other physical } \\
\text { activity }\end{array}$ & NonExPA & $\begin{array}{l}\text { PA incidental to daily activities including DIY, } \\
\text { gardening, shopping or active travel in last } 28 \text { days }\end{array}$ & Binary & $\begin{array}{c}1 \text { = 'yes' ; } \\
0=\text { 'no' }\end{array}$ & 6,303 & $(92.2)$ \\
\hline Active mental & actmental & $\begin{array}{l}\text { Cognitively active mental activities (reading, listening to } \\
\text { music, playing video or computer games) in free time }\end{array}$ & Binary & $\begin{array}{l}1 \text { = 'yes' } \\
0=\text { 'no' }\end{array}$ & 6,322 & $(92.4)$ \\
\hline Passive mental & passmental & $\begin{array}{l}\text { Cognitively passive mental activities (surfing internet, } \\
\text { watching TV) in free time }\end{array}$ & Binary & $\begin{array}{l}1 \text { = 'yes' } \\
0=\text { 'no' }\end{array}$ & 6,620 & $(96.8)$ \\
\hline Social & social & $\begin{array}{l}\text { Spending time with friends/family, eating out or visiting } \\
\text { pubs and clubs in free time }\end{array}$ & Binary & $\begin{array}{l}1 \text { = 'yes' } \\
0=\text { 'no' }\end{array}$ & 6,407 & $(93.7)$ \\
\hline Prosocial & prosocial & $\begin{array}{l}\text { Volunteering and/or giving to charity > twice in past } \\
\text { year }\end{array}$ & Binary & $\begin{array}{l}1 \text { = 'yes' } \\
0=\text { 'no' }\end{array}$ & 5,839 & $(85.4)$ \\
\hline Culture/hobbies & culthobs & $\begin{array}{l}\text { Going on days out in free time/participating in arts, } \\
\text { culture or sporting event/visit/engaging in creative } \\
\text { hobby }>\text { twice in past year }\end{array}$ & Binary & $\begin{array}{c}1 \text { = 'yes' ; } \\
0=\text { 'no' }\end{array}$ & 6,204 & $(90.7)$ \\
\hline
\end{tabular}

Note: Analysis of pooled data from waves 12-14, Taking Part Survey

\section{Estimation Strategy}

To answer the first research question, we investigated how participation in each of the seven different leisure activity sub-domains, together with the number of different types of leisure activity was associated with life satisfaction and worthwhileness by estimating separate OLS regressions for each SWB dimension, without taking account of health limitations. Variables to control for demographic characteristics and the two survey control variables were also included in the regressions, resulting in 22 variables in each of the unrestricted models. As a number of the independent and control variables proved to be statistically insignificant, and many were highly likely to be collinear with one another, to reduce the risk of multicollinearity we used nested F-tests to test restrictions on sub-sets of the variables for the two models to yield a more parsimonious version of each, with potentially different subsets of independent variables for life satisfaction and worthwhileness. The second research question was answered by next investigating how poor health mediated the relationship between participation in different leisure activity sub-domains and the two dimensions of SWB by using structural equation modelling (SEM) to estimate eight structural equation models for each SWB dimension. Each model used a different leisure activity sub-domain as the independent variable and included one mediating variable (having a limiting long-standing illness or disability) and the subset of demographic control variables that were retained in each of the restricted OLS models for life satisfaction and worthwhileness. All analyses were performed using Stata/SE 14.2 (StataCorp, 2015 ).

\section{Results}

We first compared the restricted OLS models excluding the health variable for each SWB dimension (columns (3) and (4), Table 3) to answer our main research question. Participating in a greater number of different leisure activities, and in exercise-related and other physical activity were positively associated with both life satisfaction and worthwhileness. Passive mental activities were negatively associated with both SWB dimensions. However, participation in social activities and culture/hobbies were positively associated with greater worthwhileness, but not with life satisfaction. Thus, there was some overlap in the covariates of the two dimensions of SWB, but also some factors unique to feelings of worthwhileness, notably additional leisure subdomains. We argue that there is therefore value in understanding feelings of worthwhileness of life, in addition to the more usually studied life satisfaction dimension of SWB.

Table 3 Unrestricted and restricted OLS models of life satisfaction and worthwhileness of life without controlling for health limitations 


\begin{tabular}{|c|c|c|c|c|}
\hline & \multicolumn{2}{|c|}{ UNRESTRICTED MODELS } & \multicolumn{2}{|c|}{ RESTRICTED MODELS } \\
\hline \multicolumn{5}{|c|}{ - Types of leisure activity_participated in } \\
\hline No. different types & $0.122 * * *$ & $0.134^{* * *}$ & $0.112^{* * *}$ & $0.121^{* * *}$ \\
\hline leisure activity & $(5.73)$ & $(6.51)$ & $(6.14)$ & $(6.40)$ \\
\hline Other physical & 0.0359 & $0.383^{* * *}$ & 0.0420 & $0.394^{* * *}$ \\
\hline activity & $(0.40)$ & $(4.36)$ & $(0.47)$ & $(4.50)$ \\
\hline Passive mental & $-0.464 * * *$ & $-0.443^{* * *}$ & $-0.458 * * *$ & $-0.434 * * *$ \\
\hline & $(-3.72)$ & $(-3.65)$ & $(-3.68)$ & $(-3.58)$ \\
\hline \multirow[t]{2}{*}{ Active mental } & -0.115 & -0.154 & & \\
\hline & $(-1.28)$ & $(-1.77)$ & & \\
\hline \multirow[t]{2}{*}{ Culture \& hobbies } & 0.0967 & $0.196 *$ & 0.102 & $0.209 *$ \\
\hline & $(1.06)$ & $(2.21)$ & (1.13) & $(2.37)$ \\
\hline \multicolumn{5}{|l|}{ Age-band (age $50-54=$ base) } \\
\hline \multirow{2}{*}{$55-59$} & 0.0596 & $0.162 *$ & 0.0580 & $0.162 *$ \\
\hline & $(0.78)$ & $(2.17)$ & $(0.77)$ & $(2.23)$ \\
\hline \multirow[t]{2}{*}{$60-64$} & 0.112 & $0.262^{* * *}$ & 0.111 & $0.271^{* * *}$ \\
\hline & $(1.39)$ & $(3.32)$ & $(1.40$ & $(3.56)$ \\
\hline \multirow[t]{2}{*}{$65-69$} & 0.113 & $0.239 * *$ & 0.110 & $0.249^{* *}$ \\
\hline & $(1.20)$ & $(2.62)$ & (1.19) & $(2.82)$ \\
\hline \multirow[t]{2}{*}{$70-74$} & 0.190 & $0.380^{* * *}$ & 0.189 & $0.392 * * *$ \\
\hline & $(1.91)$ & $(3.94)$ & $(1.94)$ & $(4.19)$ \\
\hline Living in a couple & $0.612^{* * *}$ & $0.403^{* * *}$ & $0.615^{* * *}$ & $0.416^{* * *}$ \\
\hline & $(13.44)$ & $(9.09)$ & $(13.59)$ & $(9.57)$ \\
\hline Not male gender & 0.0207 & $0.115^{* *}$ & 0.0199 & $0.113^{* *}$ \\
\hline & $(0.47)$ & $(2.69)$ & $(0.46)$ & $(2.68)$ \\
\hline Practising religion & $0.120 *$ & $0.175^{* * *}$ & $0.121 *$ & $0.176^{* * *}$ \\
\hline & $(2.52)$ & $(3.79)$ & $(2.55)$ & $(3.81)$ \\
\hline $1+$ child at home & 0.0751 & 0.0491 & & \\
\hline & $(0.07)$ & $(0.540$ & & \\
\hline Has degree & -0.0707 & -0.0232 & & \\
\hline & $(-1.53)$ & $(-0.52)$ & & \\
\hline Home-owner & $0.216^{* * *}$ & 0.0766 & $0.215^{* * *}$ & \\
\hline & $(4.42)$ & $(1.62)$ & $(4.42)$ & \\
\hline Non-white ethnicity & 0.0751 & 0.179 & & \\
\hline & $(0.66)$ & $(1.57)$ & & \\
\hline Lower socio-eco & $0.0672 * *$ & 0.0315 & $0.0650 * *$ & \\
\hline -mic status & $(2.74)$ & $(1.32)$ & $(2.66)$ & \\
\hline Urban resident & -0.0488 & 0.0372 & & \\
\hline & $(-0.87)$ & $(0.74)$ & & \\
\hline English not first & 0.0320 & $-0.316^{*}$ & & -0.214 \\
\hline language & $(0.24)$ & $(-2.42)$ & & $(-1.86)$ \\
\hline Employment status (in employment, & education or training $=$ & & & \\
\hline Unemployed/perm. & $-1.421 * * *$ & $-1.031 * * *$ & $-1.430 * * *$ & $-1.036^{* * *}$ \\
\hline
\end{tabular}

Page 9/19 


\begin{tabular}{cllll}
\hline Observations & 6839 & 6839 & 6839 & 6839 \\
Adjusted R-squared & 0.149 & 0.119 & 0.149 & 0.119 \\
& & & \\
\end{tabular}

Note: $\mathrm{t}$ statistics in parentheses

Note: $* \mathrm{p}<0.05, * * \mathrm{p}<0.01, * * * \mathrm{p}<0.001$

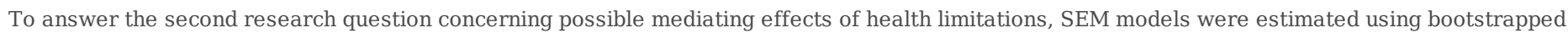

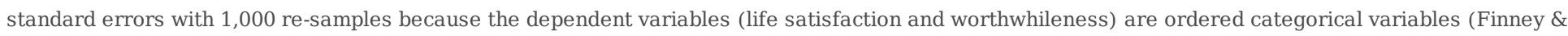

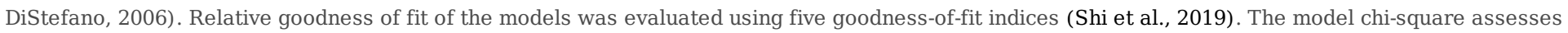

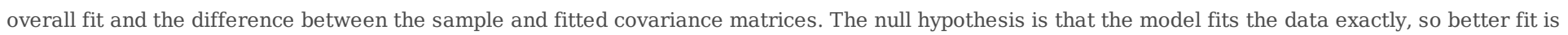

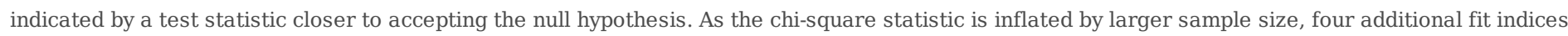

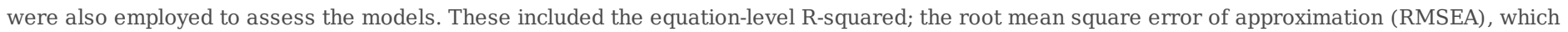

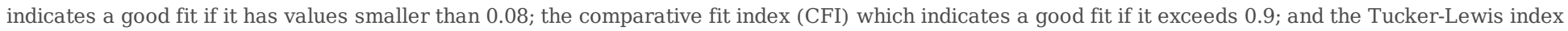
which indicates a good fit if it exceeds 0.95 .

Table 4 shows the results from eight SEM models for life satisfaction, and Table 5 shows similar results for worthwhileness. Each model has a different leisure activity sub-domain as an independent variable; having a limiting long-standing illness is the mediating variable in all models. Demographic control variables included from the restricted OLS models but not shown for reasons of space included: age-band, living in a couple, employment status, practising a religion and year of survey (for both life satisfaction and worthwhileness models); together with household equivalent income, socio-economic status and being a homeowner (for life satisfaction models); and being not male and not having English as a first language (for worthwhileness models). Figures 2 and 3 illustrate the results in path diagrams for models 1 and 9 from Table 4, also with confounding variables suppressed. The goodness-of-fit statistics suggested that the models were compatible with the data on most recommended criteria (Shi et al., 2019). Overall, the life satisfaction models fit the data

Table 4 Summary of life satisfaction health-mediated SEM model results for eight leisure variables 


\begin{tabular}{|c|c|c|c|c|c|c|c|c|c|c|c|c|}
\hline \multirow[t]{2}{*}{$\begin{array}{c}\text { Mo } \\
\text { del } \\
\text { no. }\end{array}$} & \multirow[t]{2}{*}{$\begin{array}{l}\text { Independent } \\
\text { variable (IV) }\end{array}$} & \multicolumn{4}{|c|}{ Effects of IV on life satisfaction } & \multicolumn{2}{|c|}{$\begin{array}{c}\text { Effects on life } \\
\text { satisfaction via health } \\
\text { variable as mediator }\end{array}$} & \multicolumn{5}{|c|}{ Goodness-of-fit statistics and cut-offs ${ }^{a}$} \\
\hline & & Direct & Indirect & Total & $\begin{array}{c}\text { Direct/total } \\
\%\end{array}$ & $\begin{array}{l}\text { IV to } \\
\text { health } \\
\text { (path 1) }\end{array}$ & $\begin{array}{l}\text { Health to } \\
\text { life } \\
\text { satisfaction } \\
\text { (path 3) }\end{array}$ & $\begin{array}{l}\text { Equation- } \\
\text { level R- } \\
\text { squared }\end{array}$ & $\begin{array}{l}\text { model vs } \\
\text { saturated } \\
\quad(p>)\end{array}$ & $\begin{array}{c}\text { Comparative } \\
\text { Fit Index } \\
\text { (CFI) } \\
\text { (Cut-off for } \\
\text { good fit } \geq \\
0.90)\end{array}$ & $\begin{array}{l}\text { Tucker- } \\
\text { Lewis } \\
\text { Index } \\
\text { (TLI) } \\
\text { (Cut-off } \\
\text { for } \\
\text { good fit } \\
\geq \\
0.95 \text { ) }\end{array}$ & $\begin{array}{c}\text { Root Mean } \\
\text { Square Error } \\
\text { of } \\
\text { Approximation } \\
\text { (RMSEA) } \\
\text { (Cut-off for } \\
\text { good fit } \\
<0.08 \text { ) }\end{array}$ \\
\hline 1. & $\begin{array}{l}\text { No. of } \\
\text { different } \\
\text { leisure } \\
\text { activities }\end{array}$ & $0.161^{* * *}$ & $0.009 * * *$ & $0.171^{* * *}$ & 94.7 & $-0.018 * * *$ & $-0.516^{* * *}$ & 0.189 & $\begin{array}{l}4.280 * \\
(0.369)\end{array}$ & 1.000 & 0.999 & 0.003 \\
\hline 2. & $\begin{array}{l}\text { Exercise- } \\
\text { related } \\
\text { physical } \\
\text { activity }\end{array}$ & $0.515^{* * *}$ & $0.102 * * *$ & $0.617 * * *$ & 83.1 & $-0.207 * * *$ & $-0.492 * * *$ & 0.194 & $\begin{array}{l}6.687^{*} \\
(0.153)\end{array}$ & 0.998 & 0.991 & 0.010 \\
\hline 3. & $\begin{array}{l}\text { Otherl } \\
\text { physical } \\
\text { activity }\end{array}$ & $0.550^{* * *}$ & $0.051 * * *$ & $0.600 * * *$ & 91.5 & $-0.092 * * *$ & $-0.548 * * *$ & 0.168 & $\begin{array}{l}4.060 * \\
(0.390)\end{array}$ & 1.000 & 1.000 & 0.010 \\
\hline 4. & Social & $0.771^{* * *}$ & .007 & $0.779 * * *$ & 98.9 & $-0.012 * * *$ & $-0.562 * * *$ & 0.169 & $\begin{array}{c}0.915^{*} \\
(0.882)\end{array}$ & 1.000 & 1.000 & 0.000 \\
\hline 5. & Prosocial & $0.377^{* * *}$ & -0.017 & $0.377^{* *}$ & 100.0 & 0.030 & $-0.571 * * *$ & 0.160 & $\begin{array}{l}1.233^{*} \\
(0.745)\end{array}$ & 1.000 & 1.000 & 0.000 \\
\hline 6. & Active mental & $0.362^{* * *}$ & -0.005 & $0.356^{* * *}$ & $>100.0$ & 0.009 & $-0.565^{* * *}$ & 0.162 & $\begin{array}{c}5.201 \\
(0.267)\end{array}$ & 0.999 & 0.995 & 0.007 \\
\hline 7. & Passive mental & -0.121 & $-0.039 *$ & -0.121 & n.s. & $0.069 *$ & $-0.564^{* * *}$ & 0.160 & $\begin{array}{c}1.233^{*} \\
(0.0745)\end{array}$ & 1.000 & 1.000 & 0.000 \\
\hline 8. & $\begin{array}{l}\text { Culture and } \\
\text { hobbies }\end{array}$ & $0.707^{* * *}$ & $0.025 *$ & $0.732 * * *$ & 96.8 & $-0.045^{*}$ & $-0.552^{* * *}$ & 0.165 & $\begin{array}{l}1.072 * \\
(0.784)\end{array}$ & 1.000 & 1.000 & 0.000 \\
\hline
\end{tabular}

Note: (Shi et al., 2019)

Notes: $* \mathrm{p}<0.05, * * \mathrm{p}<0.01, * * * \mathrm{p}<0.001$. n.s. $=$ not statistically significant. Demographic controls and constant term suppressed for space reasons

Table 5 Summary of worthwhileness health-mediated SEM results for eight leisure variables 


\begin{tabular}{|c|c|c|c|c|c|c|c|c|c|c|c|c|}
\hline \multirow{2}{*}{$\begin{array}{l}\text { Mo } \\
\text { del } \\
\text { no. }\end{array}$} & \multirow[t]{2}{*}{$\begin{array}{l}\text { Independent } \\
\text { variable (IV) }\end{array}$} & \multicolumn{4}{|c|}{ Effects of IV on worthwhileness } & \multicolumn{2}{|c|}{$\begin{array}{c}\text { Effects on worthwhileness } \\
\text { via health variable as } \\
\text { mediator }\end{array}$} & \multicolumn{5}{|c|}{ Goodness-of-fit statistics and cut-offs ${ }^{\mathrm{a}}$} \\
\hline & & Direct & Indirect & Total & $\begin{array}{c}\text { Direct/total } \\
\%\end{array}$ & $\begin{array}{l}\text { IV to } \\
\text { health } \\
\text { (path 1) }\end{array}$ & $\begin{array}{c}\text { Health to } \\
\text { worthwhileness } \\
\text { (path 3) }\end{array}$ & $\begin{array}{l}\text { Equation- } \\
\text { level R- } \\
\text { squared }\end{array}$ & $\begin{array}{l}\text { model vs } \\
\text { saturated } \\
\quad(p>)\end{array}$ & $\begin{array}{l}\text { Comparative } \\
\text { Fit Index } \\
\text { (CFI) } \\
\text { (Cut-off for } \\
\text { good fit } \geq \\
0.90)\end{array}$ & $\begin{array}{l}\text { Tucker- } \\
\text { Lewis } \\
\text { Index } \\
\text { (TLI) } \\
\text { (Cut-off } \\
\text { for } \\
\text { good fit } \\
\geq \\
0.95 \text { ) }\end{array}$ & $\begin{array}{c}\text { Root Mean } \\
\text { Square Error } \\
\text { of } \\
\text { Approximation } \\
\text { (RMSEA) } \\
\text { (Cut-off for } \\
\text { good fit } \\
<0.08 \text { ) }\end{array}$ \\
\hline 9. & $\begin{array}{l}\text { No. of } \\
\text { different } \\
\text { leisure } \\
\text { activities }\end{array}$ & $0.203^{* *}$ & $0.007 * * *$ & $0.210^{* * *}$ & 96.7 & $-0.018 * * *$ & $-0.364 * * *$ & 0.173 & $\begin{array}{l}15.465 \\
(0.017)\end{array}$ & 0.993 & 0.975 & 0.015 \\
\hline 10. & $\begin{array}{l}\text { Exercise- } \\
\text { related } \\
\text { physical } \\
\text { activity }\end{array}$ & $0.601 * * *$ & $0.076 * * *$ & $0.677 * * *$ & 88.6 & $-0.207^{* * *}$ & $-0.366 * * *$ & 0.162 & $\begin{array}{l}36.224 \\
(0.000)\end{array}$ & 0.978 & 0.914 & 0.027 \\
\hline 11. & $\begin{array}{l}\text { Other } \\
\text { physical } \\
\text { activity }\end{array}$ & $0.992 * * *$ & $0.039 * * *$ & $1.023 * * *$ & 96.2 & $-0.092 * * *$ & $-0.425^{* * *}$ & 0.144 & $\begin{array}{l}40.363 \\
(0.000)\end{array}$ & 0.972 & 0.891 & 0.029 \\
\hline 12. & Social & $1.029 * * *$ & .006 & $1.034^{* * *}$ & 99.5 & $-0.012^{* * *}$ & $-0.450 * * *$ & 0.139 & $\begin{array}{l}39.833 \\
(0.000)\end{array}$ & 0.971 & 0.889 & 0.029 \\
\hline 13. & Prosocial & $0.538^{* * *}$ & -0.014 & $0.524 * * *$ & $>100.0$ & 0.030 & $-0.462 * * *$ & 0.132 & $\begin{array}{l}39.770 \\
(0.000)\end{array}$ & 0.9710 & 0.884 & 0.029 \\
\hline 14. & $\begin{array}{l}\text { Active } \\
\text { mental }\end{array}$ & $0.497 * * *$ & -0.004 & $0.493 * * *$ & $>100.0$ & 0.009 & $-0.459 * * *$ & 0.126 & $\begin{array}{l}45.555 \\
(0.000)\end{array}$ & 0.963 & 0.866 & 0.031 \\
\hline 15. & $\begin{array}{l}\text { Passive } \\
\text { mental }\end{array}$ & $0.046^{*}$ & $-0.032 *$ & 0.018 & n.s. & $0.069 *$ & $-0.046^{* * *}$ & 0.122 & $\begin{array}{l}50.882 \\
(0.000)\end{array}$ & 0.957 & 0.836 & 0.033 \\
\hline 16. & $\begin{array}{l}\text { Culture and } \\
\text { hobbies }\end{array}$ & $0.957 * * *$ & $0.019 *$ & $0.976 * * *$ & 98.5 & $-0.045^{*}$ & $-0.433^{* * *}$ & 0.144 & $\begin{array}{l}33.246 \\
(0.000)\end{array}$ & 0.977 & 0.913 & 0.026 \\
\hline
\end{tabular}

Note: a (Shi et al., 2019)

Notes: $* \mathrm{p}<0.05, * * \mathrm{p}<0.01, * * * \mathrm{p}<0.001$. n.s. = not statistically significant. Demographic controls and constant term suppressed for space reasons

[Insert Figure 2 here]

slightly better than the worthwhileness models, since equation-level R-squareds were higher; the results of model chi-squared tests were statistically significant at the 5\% level; comparative fit and Tucker- Lewis indices were higher and root mean square error of approximations were lower. The worthwhileness models did not meet the recognised criteria for the model chi-squared tests nor, for some specifications, for the Tucker Lewis index, but did meet the cut-offs for the comparative fit index and the root mean square error of approximation. Overall, therefore, the models appear to fit the data reasonably well.

Including a measure of poor health as a mediating variable in the analyses affected the relationships between different leisure activity sub-domains and the two dimensions of SWB differently. Having a limiting long-standing illness or disability was consistently associated with lower life satisfaction and worthwhileness across all the leisure activity sub-domains (path 3, Tables 4 and 5 and figures 1 and 2). The absolute size of the negative coefficient on the health variable was in all models larger for life satisfaction than for feelings of worthwhileness of life. The sizes of the path 1 coefficients varied by type of leisure activity, but were identical across the two SWB dimensions, as expected, given the dependent variable plays no role in that part of the indirect pathway. The degree of mediation is given by the ratio of the direct effect of a leisure activity on SWB as a proportion of the total effect. Mediation is greater where the direct effect of the activity on the measure of SWB is a lower percentage of the total effect. The mediating effect of having a limiting long-standing illness was always greater on life satisfaction than worthwhileness for any given any given leisure activity. The path diagrams illustrate how the impacts of participating in a greater number of different types of leisure activity on the two measures of SWB (models 1 and 9) were mediated by having a limiting long-standing illness or disability. Tables 4 and 5 show that the mediating effect of having a limiting long-standing illness or disability on SWB was greatest for both types of physical activity, although the mediating effect was greater for exercise-related physical activity (models 2 and 10) than 


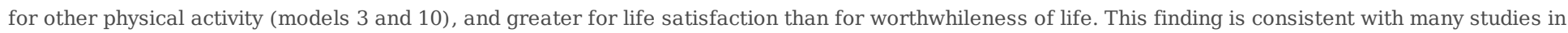

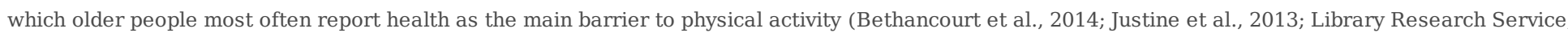
2010; Moschny et al., 2011; Schutzer \& Graves, 2004).

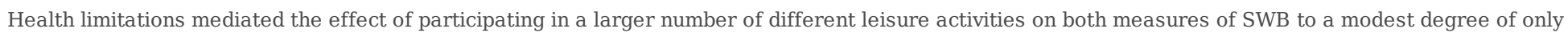

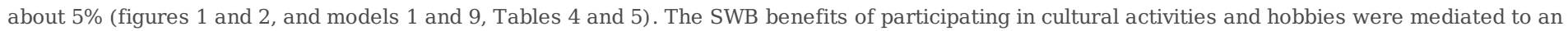

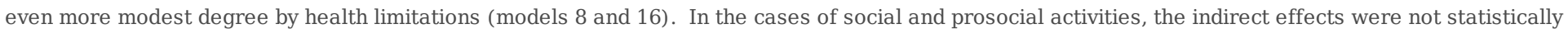

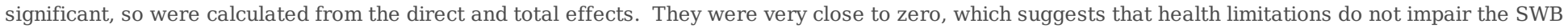

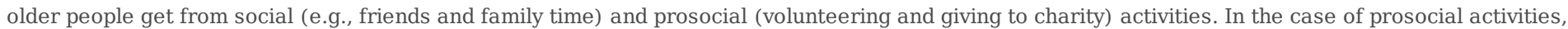

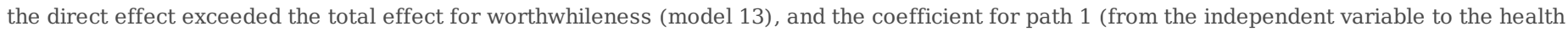

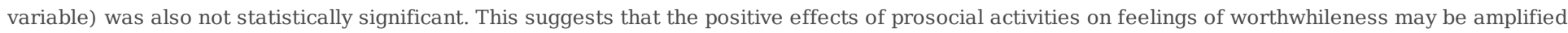

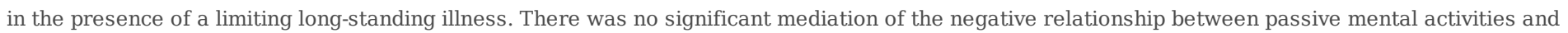

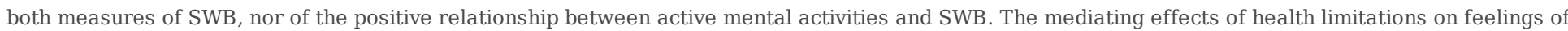

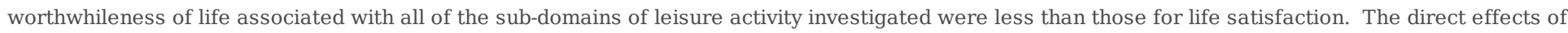

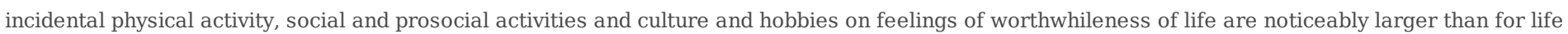
satisfaction.

\section{Discussion}

We found, in answer to our first research question about the unmediated associations between different leisure activities and the two SWB dimensions that passive mental activities had a negative relationship with both SWB dimensions, consistent with evidence that TV viewing time is negatively associated with mental wellbeing in adults (Dempsey et al., 2014). It was also observed that participating in a greater number of different types of leisure activity and exercise-related physical activity were positively associated with both dimensions of SWB. The first result is consistent with the activity theory of ageing. Worthwhileness was observed to also be positively associated with participation in social and culture/hobby activities, which is consistent with existing research (Fancourt \& Steptoe, 2018b; Steptoe \& Fancourt, 2019). In answer to our second research question of whether health limitations mediate relationships between leisure activity participation and SWB, we observed different results depending on the type of leisure activity. The positive association of prosocial and active mental activities and the negative association of passive mental activities with both dimensions of SWB appeared unaffected by health limitations. For active mental activities, the positive association with SWB was slightly amplified by having a limiting long-standing illness or disability, as was the positive association of prosocial activities with worthwhileness. Of all the leisure activity sub-domains, participation in social activities had the largest positive direct effect on feelings of worthwhileness and life satisfaction with very small mediation effects from having a limiting long-standing illness. Participation in culture/hobbies was also associated directly with higher worthwhileness and life satisfaction with only small mediation effects from having health limitations. At the other extreme, the SWB associated with physical activities was most impaired by having health limitations that are more common with age. However, it is encouraging that one quarter of our sample were still participating in exercise-related physical activity and $45 \%$ in other physical activity, despite having health limitations. Many models of successful ageing describe a process of selective optimisation with compensation as a way of proactively adapting to the limitations posed by ageing but still enjoying life (Baltes \& Carstensen, 2003; Carpentieri et al., 2017; Freund \& Baltes, 1998). Those who continue to participate in sport and exercise may have found new activities to replace the ones they can no longer do, and/or adapted how they participate in some way, such as enjoying lower-impact activities like cycling, walking or swimming (Davison \& Cowan, 2020), or specially adapted sports such as walking football (Cholerton et al., 2020) and netball.

Finally, the study addressed the question of whether health limitations affected relationships between leisure activity participation and life satisfaction differently from relationships between leisure activity participation and feelings of worthwhileness. Our results showed that participating in any form of leisure activity had a greater direct effect on worthwhileness after accounting for health limitations than on life satisfaction, which accords with the meaning of worthwhileness as deriving mainly from what you do, whether for work or leisure (Office for National Statistics, 2018). There is also some support for activity theories of successful ageing in the presence of health limitations from the positive direct relationship found between the total number of different leisure activities engaged in and both life satisfaction and worthwhileness, supporting others' calls for efforts to increase participation in social leisure activities of those with health problems (Galenkamp et al., 2016; Galenkamp \& Deeg, 2016).

\section{Strengths And Limitations}

A key strength of the study is the relatively large sample size, with good coverage of the English population in terms of demographic characteristics. The dataset used contains a rich set of variables on the personal characteristics of participants and leisure activities. The study also used common validated instruments for measuring both dimensions of SWB, and having a limiting long-standing illness or disability, as 
developed by the ONS. The main novelty of this study is the use of structural equation modelling to examine how health limitations affect two dimensions of subjective wellbeing derived from participation in a range of leisure activity sub-domains. Most previous studies of older peoples' subjective wellbeing and choice of leisure activities focus on either life satisfaction or - less frequently - worthwhileness of life alone, and none we could find model health limitations as a mediating factor between leisure participation and SWB. This study is the first to compare the mediation effects for both life satisfaction and worthwhileness of life and note different effects for any given leisure activity sub-domain. The study has a number of limitations. It is an observational study using cross-sectional data, and so causal links cannot be discerned. The dataset does not allow the inclusion of controls for social or environmental context for leisure activities, which are known to be important influences on the enjoyment of and motivation for different activities (Finlay et al., 2015; Hancock et al., 2020). The measures of participation are binary, so a dose-response relationship between frequency of participation and SWB cannot be estimated. TPS participation data relies on recall of the survey participants which can be unreliable, especially in older people, whose short-term memory is more likely to be impaired (Verhaeghen, 2013), and finally the survey does not include older people living in care homes and hospitals, whose leisure activities and SWB are likely to exhibit different patterns from adults living in the community.

\section{Conclusion}

These results suggest that deepening understanding of the role that leisure activities play in generating feelings of worthwhileness for those with limiting long-term health conditions could help with the design of programmes and policies to improve the lives of older people. The main contribution of this study is to confirm that older people can continue to lead lives they feel are worthwhile, despite health limitations, through participating in a range of types of leisure activity, and that such participation is more important for worthwhileness than for life satisfaction. Although physical activity is an important public health priority because it helps people remain healthy and independent as they age, focusing policy and provision on additional activities that contribute to feelings of worthwhileness of life for older people is likely to help improve their wellbeing and contribute to successful ageing, despite declining health. With the lengthening of life expectancy, the importance of ensuring access to a wide range of leisure activities - especially those that provide social and prosocial opportunities - for older people's wellbeing must not be overlooked.uture research should examine what role unequal access to leisure opportunities may play in the growing gap in healthy life expectancy between the richest and poorest older people in the UK (Marmot et al., 2020).

\section{References}

Adams, K. B., Leibbrandt, S., \& Moon, H. (2011). A critical review of the literature on social and leisure activity and wellbeing in later life. In Ageing and Society. https://doi.org/10.1017/S0144686X10001091

Alessi, C., \& Rashbrook, E. (2016, October 1). Ageing well: How can we make longer lives healthier? Public Health Matters Blog. Retrieved 15 February, 2021, from httpss://publichealthmatters.blog.gov.uk/2016/10/02/ageing-well-how-can-we-make-longer-lives-healthier

Anyaegbu, G. (2010). Using the OECD equivalence scale in taxes and benefits analysis. Economic and Labour Market Review, 4(1), 49-54. https://doi.org/10.1057/elmr.2010.9

Bae, W., Ik Suh, Y., Ryu, J., \& Heo, J. (2017). Physical activity levels and well-being in older adults. Psychological Reports, 120(2). https://doi.org/10.1177/0033294116688892

Baltes, M., \& Carstensen, L. L. (2003). The process of successful aging: Selection, optimization, and compensation. In U. Staudinger \& U. Lindenberger (Eds.), Understanding Human Development. Springer US. https://doi.org/https://doi.org/10.1007/978-1-4615-0357-6_5

Bethancourt, H. J., Rosenberg, D. E., Beatty, T., \& Arterburn, D. E. (2014). Barriers to and facilitators of physical activity program use among older adults. Clinical Medicine and Research, 12(1-2), 10-20. https://doi.org/10.3121/cmr.2013.1171

Biedenweg, K., Meischke, H., Bohl, A., Hammerback, K., Williams, B., Poe, P., \& Phelan, E. A. (2014). Understanding older adults' motivators and barriers to participating in organized programs supporting exercise behaviors. Journal of Primary Prevention, 35(1), 1-11. https://doi.org/10.1007/s10935-013-0331-2

Bowling, A., \& Dieppe, P. (2005). What is successful ageing and who should define it? British Medical Journal, 331(7531), 1548-1551. https://doi.org/10.1136/bmj.331.7531.1548

Brajša-Žganec, A., Merkaš, M., \& Šverko, I. (2011). Quality of life and leisure activities: How do leisure activities contribute to subjective wellbeing? Social Indicators Research, 102(1), 81-91. https://doi.org/10.1007/s11205-010-9724-2

Brown, J. L., MacDonald, R., \& Mitchell, R. (2015). Are people who participate in cultural activities more satisfied with life? Social Indicators Research, 122(1), 135-146. https://doi.org/10.1007/s11205-014-0678-7 
Carpentieri, J. D., Elliott, J., Brett, C. E., \& Deary, I. J. (2017). Adapting to aging: Older people talk about their use of selection, optimization, and compensation to maximize well-being in the context of physical decline. Journals of Gerontology - Series B Psychological Sciences and Social Sciences, 72(2), 351-361. https://doi.org/10.1093/geronb/gbw132

Caspersen, C. J., Powell, K. E., \& Christenson, G. M. (1985). Physical activity, exercise, and physical fitness: definitions and distinctions for healthrelated research. Public Health Reports (Washington, D.C.: 1974), 100(2), 126-131. https://doi.org/10.2307/20056429

Chang, P.-J., Wray, L., \& Lin, Y. (2014). Social relationships, health and leisure in older adults. Health Psychology, $33(6), 516-523$. https://doi.org/10.1007/s10741-014-9462-7

Cholerton, R., Breckon, J., Butt, J., \& Quirk, H. (2020). Experiences influencing walking football initiation in 55- To 75-year-old adults: A qualitative study. Journal of Aging and Physical Activity, 28(4), 521-533. https://doi.org/10.1123/JAPA.2019-0123

Clark, A. E. (2018). Four decades of the economics of happiness: Where next? Review of Income and Wealth, 64(2), $245-269$. https://doi.org/10.1111/roiw.12369

Cox, L., Coleman, L., \& Roker, D. (2006). Understanding participation in sport: What determines sports participation among recently retired people? In Sport England (Sport England Research Reports, Issue February). Retrieved 21 January, 2019, from https://sport-england-production-files.s3.euwest-2.amazonaws.com

Crespo, R. F., \& Mesurado, B. (2015). Happiness economics, eudaimonia and positive psychology: From happiness economics to flourishing economics. Journal of Happiness Studies, 16(4), 931-946. https://doi.org/10.1007/s10902-014-9541-4

Davison, R., \& Cowan, D. (2020). Sports participation and ageing - influence and impact (Issue May). Retrieved 10 October, 2020, from https://www.oss.scot/wp-content/uploads/2020/05/Sports-Participation-and-Ageing-Paper.pdf

Dempsey, P. C., Howard, B. J., Lynch, B. M., Owen, N., \& Dunstan, D. W. (2014). Associations of television viewing time with adults' well-being and vitality. Preventive Medicine, 69, 69-74. https://doi.org/10.1016/j.ypmed.2014.09.007

Department for Culture Media and Sport. (2018, September 17). The Taking Part Survey of culture, leisure and sport, 2016-2017; Adult and child data. UK Data Service. https://doi.org/10.5255/UKDA-SN-8378-2

Department for Culture Media and Sport. (2019, January 31). The Taking Part Survey of culture, leisure and sport, 2017-2018; Adult and child data. UK Data Service. https://doi.org/10.5255/UKDA-SN-8442-1

Department for Culture Media and Sport. (2020, April 27). The Taking Part Survey of culture, leisure and sport, 2018-2019; Adult and child data. UK Data Service. https://doi.org/10.5255/UKDA-SN-8631-1

Department for Digital Culture Media and Sport. (2020, March). Taking Part Survey. Guidance. Retrieved 17 July, 2020 , from https://www.gov.uk/guidance/taking-part-survey

Dolan, P. (2014). Happiness by design: Finding pleasure and purpose in everyday life. Allen Lane. https://doi.org/10.5749/j.ctvwh8f4z

Dolan, P., Kavetosos, G., \& Vlaev, I. (2014). The happiness workout. Social Indicators Research, 119(3), 1363-1377. https://doi.org/10.1007/s

Dolan, P., \& Kudrna, L. (2016). Sentimental hedonism: Pleasure, purpose, and public policy. In J. Vittersø (Ed.), Handbook of Eudaimonic WellBeing (pp. 437-452). Springer International Publishing. https://doi.org/10.1007/978-3-319-42445-3_29

Dolan, P., Peasgood, T., \& White, M. (2008). Do we really know what makes us happy? A review of the economic literature on the factors associated with subjective well-being. Journal of Economic Psychology, 29(1), 94-122. https://doi.org/10.1016/j.joep.2007.09.001

Downward, P., Hallmann, K., \& Rasciute, S. (2018). Exploring the interrelationship between sport, health and social outcomes in the UK: Implications for health policy. European Journal of Public Health, 28(1), 99-104. https://doi.org/10.1093/eurpub/ckx063

Fancourt, D., Aughterson, H., Finn, S., Walker, E., \& Steptoe, A. (2021). How leisure activities affect health: a narrative review and multi-level theoretical framework of mechanisms of action. The Lancet Psychiatry. https://doi.org/https://doi.org/10.1016/S2215-0366(20)30384-9

Fancourt, D., \& Steptoe, A. (2018a). Community group membership and multidimensional subjective well-being in older age. Journal of Epidemiology and Community Health, 72(5), 376-382. https://doi.org/10.1136/jech-2017-210260

Fancourt, D., \& Steptoe, A. (2018b). Cultural engagement predicts changes in cognitive function in older adults over a 10 year period: Findings from the English Longitudinal Study of Ageing. Scientific Reports, 8(1), 1-8. https://doi.org/10.1038/s41598-018-28591-8

Page 15/19 
Finlay, J., Franke, T., McKay, H., \& Sims-Gould, J. (2015). Therapeutic landscapes and wellbeing in later life: Impacts of blue and green spaces for older adults. Health and Place, 34, 97-106. https://doi.org/10.1016/j.healthplace.2015.05.001

Finney, S. J., \& DiStefano, C. (2006). Non-normal and categorical data in structural equation modelling. In G. R. Hancock \& R. O. Mueller (Eds.), Structural Equation Modelling: a second course (pp. 269-313).

Fortier, M. S., \& Morgan, T. L. (2021). How optimism and physical activity interplay to promote happiness. Current Psychology, December 2020. https://doi.org/10.1007/s12144-020-01294-y

Freund, A. M., \& Baltes, P. B. (1998). Selection, optimization, and compensation as strategies of life management: Correlations with subjective indicators of successful aging. Psychology and Aging, 13(4), 531-543.

Galenkamp, H., \& Deeg, D. J. H. (2016). Increasing social participation of older people: are there different barriers for those in poor health? Introduction to the special section. European Journal of Ageing, 13(2), 87-90. https://doi.org/10.1007/s10433-016-0379-y

Galenkamp, H., Gagliardi, C., Principi, A., Golinowska, S., Moreira, A., Schmidt, A. E., Winkelmann, J., Sowa, A., van der Pas, S., \& Deeg, D. J. H. (2016). Predictors of social leisure activities in older Europeans with and without multimorbidity. European Journal of Ageing, 13(2), $129-143$. https://doi.org/10.1007/s10433-016-0375-2

Hallmann, K., Artime, C. M., Breuer, C., Dallmeyer, S., \& Metz, M. (2017). Leisure participation: modelling the decision to engage in sports and culture. Journal of Cultural Economics, 41(4), 467-487. https://doi.org/10.1007/s10824-016-9275-8

Hancock, K. E., Downward, P., \& Sherar, L. B. (2020). Exploring the pleasure and purpose associated with older people's activities using ecological momentary analysis: an observational study. Journal of Aging and Physical Activity, 1-16. https://doi.org/https://doi.org/10.21203/rs.3.rs29145/

Havighurst, R. J. (1961). Successful aging. The Gerontologist, 1(1), 8-13. https://doi.org/10.1093/geront/1.1.8

Ihle, A., Gouveia, É. R., Gouveia, B. R., van der Linden, B. W. A., Sauter, J., Gabriel, R., Oris, M., Fagot, D., \& Kliegel, M. (2017). The Role of leisure activities in mediating the relationship between physical health and wellbeing: Differential patterns in old and very old age. Gerontology, 63(6), 560-571. https://doi.org/10.1159/000477628

lizuka, A., Suzuki, H., Ogawa, S., Kobayashi-Cuya, K. E., Kobayashi, M., Takebayashi, T., \& Fujiwara, Y. (2019). Can cognitive leisure activity prevent cognitive decline in older adults? A systematic review of intervention studies. Geriatrics \& Gerontology International, O(0), 1-14.

https://doi.org/10.1111/ggi.13671

Jenkins, A., \& Mostafa, T. (2015). The effects of learning on wellbeing for older adults in England. Ageing and Society, 35(10), 2053-2070. https://doi.org/10.1017/S0144686X14000762

Joshanloo, M. (2016). Revisiting the empirical distinction between hedonic and eudaimonic aspects of wellbeing using exploratory structural equation modelling. Journal of Happiness Studies, 17(5), 2023-2036. https://doi.org/10.1007/s10902-015-9683-z

Justine, M., Azizan, A., Hassan, V., Salleh, Z., \& Manaf, H. (2013). Barriers to participation in physical activity and exercise among middle-aged and elderly individuals. Singapore Medical Journal, 54(10), 581-586. https://doi.org/10.11622/smedj.2013203

Kaliterna Lipovčan, L., Brkljačić, T., Prizmić Larsen, Z., Brajša-Žganec, A., \& Franc, R. (2018). Leisure activities and the subjective well-being of older adults in Croatia. GeroPsych: The Journal of Gerontopsychology and Geriatric Psychiatry, 31(1), 31-39.

Kuykendall, L., Tay, L., \& Ng, V. (2015). Leisure engagement and subjective well-being: A meta-analysis. Psychological Bulletin, 141(2), 364-403. https://doi.org/10.1037/a0038508

Lam, J., \& Garcia, J. (2019). Solitary days, solitary activities and associations with wellbeing among older adults. The Journals of Gerontology. Series B, Psychological Sciences and Social Sciences. https://doi.org/10.1093/geronb/gbz036

Lee, Y., Min, J., \& Chi, I. (2018). Life transitions and leisure activity engagement in later life: findings from the Consumption and Activities Mail Survey (CAMS). Ageing and Society, 38(8), 1603-1623. https://doi.org/10.1017/S0144686X17000216

Library Research Service. (2010). Barriers to sports and physical activity (Issue Research Paper 18/10, January). Retrieved 14 January, 2019, from archive.niassembly.gov.uk/researchandlibrary/2010/1810.pdf 
Marmot, M., Allen, J., Boyce, T., Goldblatt, P., Morrison, J., Michael Marmot, by, of Jessica Allen, consisted, Allen, M., Ntouva, A., Porritt Peter Goldblatt, F., Beswick, L., Bourke, D., Codling, K., Hallam, P., Munro, A., Dixon, J., Bibby, J., Cockin, J., Elwell Sutton, T., ... Wiseman, A. (2020). Health equity in England: The Marmot Review 10 years on (Vol. 10).

Mckenna, K., Broome, K., \& Liddle, J. (2007). What older people do: Time use and exploring the link between role participation and life satisfaction in people aged 65 years and over. Australian Occupational Therapy Journal, 54(4), 273-284. https://doi.org/10.1111/j.1440-1630.2007.00642.x

Michèle, J., Guillaume, M., Alain, T., Nathalie, B., Claude, F., \& Kamel, G. (2019). Social and leisure activity profiles and well-being among the older adults: a longitudinal study. Aging and Mental Health, 23(1), 77-83. https://doi.org/10.1080/13607863.2017.1394442

Moschny, A., Platen, P., Klaaßen-mielke, R., Trampisch, U., \& Hinrichs, T. (2011). Barriers to physical activity in older adults in Germany. International Journal of Behavioural Nutrition and Physical Activity, 8(121), 1-10. http://www.ijbnpa.org/content/pdf/1479-5868-8-121.pdf

Musich, S., Wang, S. S., Kraemer, S., Hawkins, K., \& Wicker, E. (2018). Purpose in life and positive health outcomes among older adults. Population Health Management, 21(2), 139-147. https://doi.org/10.1089/pop.2017.0063

Narushima, M., Liu, J., \& Diestelkamp, N. (2013). The association between lifelong learning and psychological well-being among older adults: Implications for interdisciplinary health promotion in an aging society. Activities, Adaptation \& Aging, 37(3), 239-250.

https://doi.org/10.1080/01924788.2013.816834

Nilsson, I., Häggström Lundevaller, E., \& Fisher, A. G. (2017). The relationship between engagement in leisure activities and self-rated health in later life. Activities, Adaptation and Aging, 41(2), 175-190. https://doi.org/10.1080/01924788.2017.1306384

Nixon, O. (2020, June 9). Activity restriction harmonised standard. Government Statistical Service Policy and Guidance Hub.

Office for National Statistics. (2013, October 23). National wellbeing. Collection: Reports and Publications Relating to the National Wellbeing Programme Launched by the Prime Minister in 2010. Retrieved 14 April, 2018, from https://www.gov.uk/government/collections/nationalwellbeing

Office for National Statistics. (2018, September 26). Personal well-being in the UK: Quality and methodology information. Methodology. Retrieved 4 February, 2019, from https://www.ons.gov.uk/peoplepopulationandcommunity/wellbeing/methodologies/personalwellbeingintheukqmi

Ong, A. D., \& Patterson, A. (2016). Eudaimonia, Aging, and Health: A Review of Underlying Mechanisms. In J. Vitters $\varnothing$ (Ed.), Handbook of Eudaimonic Well-Being (pp. 371-378). Springer International Publishing. https://doi.org/10.1007/978-3-319-42445-3_24

Paggi, M. E., Jopp, D., \& Hertzog, C. (2016). The importance of leisure activities in the relationship between physical health and well-being in a life span sample. Gerontology, 62(4), 450-458. https://doi.org/10.1159/000444415

Pinquart, M. (2002). Creating and maintaining a purpose in life in old age: A meta-analysis. Ageing International, 27(2), 90-114.

Rasciute, S., \& Downward, P. (2010). Health or happiness? What is the impact of physical activity on the individual? Kyklos, 63(2), $256-270$. https://doi.org/10.1111/j.1467-6435.2010.00472.x

Ryff, C. D. (2017). Eudaimonic well-being, inequality, and health: Recent findings and future directions. International Review of Economics, 64(2), 159-178. https://doi.org/10.1007/s12232-017-0277-4

Ryu, J., \& Heo, J. (2018). Relationships between leisure activity types and well-being in older adults. Leisure Studies, 37(3), 331-342. https://doi.org/10.1080/02614367.2017.1370007

Schulz, P., Schulte, J., Raube, S., Disouky, H., \& Kandler, C. (2017). The role of leisure interest and engagement for subjective well-being. Journal of Happiness Studies, 19(4), 1-16. https://doi.org/10.1007/s10902-017-9863-0

Schutzer, K. A., \& Graves, B. S. (2004). Barriers and motivations to exercise in older adults. Preventive Medicine, 39(5), $1056-1061$. https://doi.org/10.1016/j.ypmed.2004.04.003

Sharifian, N., \& Grühn, D. (2019). The differential impact of social participation and social support on psychological well-being: Evidence from the Wisconsin longitudinal study. International Journal of Aging and Human Development, 88(2), 107-126.

https://doi.org/10.1177/0091415018757213

Shi, D., Lee, T., \& Maydeu-Olivares, A. (2019). Understanding the model size effect on SEM fit indices. Educational and Psychological Measurement, 79(2), 310-334. https://doi.org/10.1177/0013164418783530

Page 17/19 
Son, J., \& Wilson, J. (2012). Volunteer work and hedonic, eudemonic, and social well-being. Sociological Forum, $27(3), 658-681$.

https://doi.org/10.1111/j.1573-7861.2012.01340.x

StataCorp. (2015). Stata Statistical Software (/SE 14.2). College Station, Tx: StataCorp.

Stebbins, R. A. (2005). Choice and experiential definitions of leisure. Leisure Sciences, 27, 349-352.

https://doi.org/10.1080/01490400590962470

Stenner, P., \& Mcfarquhar, T. (2011). Older people and "active ageing": Subjective aspects of ageing actively. Journal of Health Psychology, 16, 467-477. https://doi.org/10.1177/1359105310384298

Steptoe, A., Deaton, A., \& Stone, A. A. (2015). Subjective wellbeing, health, and ageing. The Lancet, 385(9968), 640-648.

https://doi.org/10.1016/S0140-6736(13)61489-0

Steptoe, A., \& Fancourt, D. (2019). Leading a meaningful life at older ages and its relationship with social engagement, prosperity, health, biology, and time use. Proceedings of the National Academy of Sciences of the United States of America, 116(4), 1207-1212.

https://doi.org/10.1073/pnas.1814723116

Steptoe, A., \& Fancourt, D. (2020). An outcome-wide analysis of bidirectional associations between changes in meaningfulness of life and health, emotional, behavioural, and social factors. Scientific Reports, 10(1). https://doi.org/10.1038/s41598-020-63600-9

Tkatch, R., Musich, S., MacLeod, S., Kraemer, S., Hawkins, K., Wicker, E. R., \& Armstrong, D. G. (2017). A qualitative study to examine older adults' perceptions of health: Keys to aging successfully. Geriatric Nursing, 38(6), 485-490. https://doi.org/10.1016/j.gerinurse.2017.02.009

Urtamo, A., Jyväkorpi, S. K., \& Strandberg, T. E. (2019). Definitions of successful ageing: A brief review of a multidimensional concept. Acta Biomedica, 90(2), 359-363. https://doi.org/10.23750/abm.v90i2.8376

Verghese, J., Lipton, R. B., Katz, M. J., Hall, C. B., Derby, C. A., Kuslansky, G., Ambrose, A. F., Sliwinski, M., \& Buschke, H. (2003). Leisure activities and the risk of dementia in the elderly. The New England Journal of Medicine, 348(25), 2508-2516. https://doi.org/10.1056/NEJMoa022252

Verhaeghen, P. (2013). The elements of cognitive aging: Meta-analyses of age-related differences in processing speed and their consequences. Oxford University Press. https://doi.org/10.1093/acprof:oso/9780195368697.001.0001

Versus Arthritis. (2019). The state of musculoskeletal health, 2019. In Versus Arthritis. Retrieved 15 January, 2021, from https://www.versusarthritis.org/media/14594/state-of-musculoskeletal-health-2019.pdf

What Works Centre for Wellbeing. (2021). What matters for our sense of purpose? (Issue March). Retrieved 30 March, 2021, from https://whatworkswellbeing.org/wp-content/uploads/2021/03/purpose-whatworkswellbeing-March2021.pdf

Zhang, Z., \& Chen, W. (2019). A systematic review of the relationship between physical activity and happiness. Journal of Happiness Studies, 20(4), 1305-1322. https://doi.org/10.1007/s10902-018-9976-0

\section{Figures}

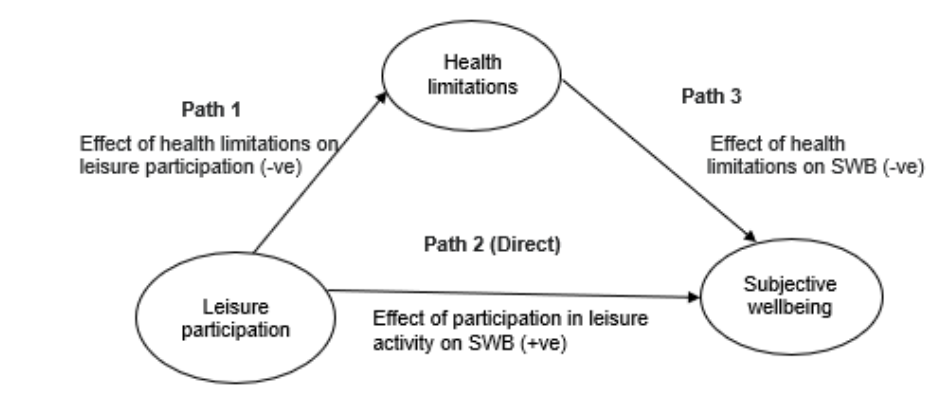

Note: Demographic controls omitted for clarity

\section{Figure 1}

Hypothesised structural relationship between leisure activity participation, health limitations and subjective wellbeing 


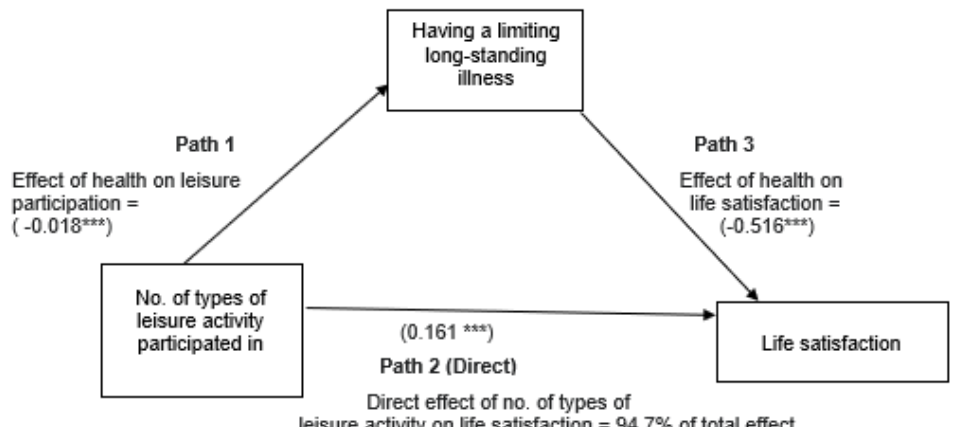

leisure activity on life satisfaction $=94.7 \%$ of total effect

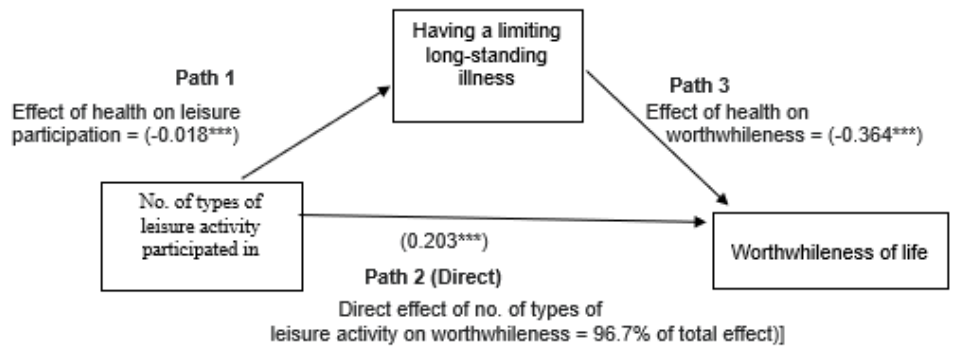

Note: ${ }^{*} p<0.05, * * 0<0.01,{ }^{* * *} p<0.001$

Note: Demographic controls suppressed for clarity

\section{Figure 2}

Structural equation models predicting life satisfaction and worthwhileness as a function of the number of different types of leisure activity and having a limiting long-standing illness in adults aged 50+ 